\title{
Environmental Impact Assessment of a Water Transfer Project
}

\author{
Maryam Pazoki ${ }^{1, *}$; Masoome Ahmadi Pari ${ }^{1}$; Peyman Dalaei ${ }^{1}$; Reza Ghasemzadeh ${ }^{1}$ \\ ${ }^{1}$ Department of Environment, University of Tehran, Tehran, IR Iran \\ *Corresponding author: Maryam Pazoki, Department of Environment, University of Tehran, Tehran, IR Iran. Tel: +98-9123186604, E-mail: mpazoki@ut.ac.ir
}

Received: January 24, 2015; Revised: April 26, 2015; Accepted: May 18, 2015

\begin{abstract}
Background: Reliable water supplies for drinking and agriculture are some of the objectives for the sustainable development of every country. However, constructed facilities such as dams and irrigation networks and drainage can exert positive and negative effects directly or indirectly on the environment. The environmental impact assessment is a method for identifying the positive and negative effects caused by a plan and suggests performance management best practices aimed at lessening the negative impacts and augmenting the positive ones.

Objectives: The present study sought to evaluate the environmental impacts of the water transfer project of the Jooban Dam in two phases of preparation and operation.

Materials and Methods: A checklist containing the positive, negative, short-term, and long-term effects as well as the continuation and probable occurrence of these effects was used.

Results: The results showed that the negative environmental and social impacts of the project outweighed the positive impacts in terms of type, number, and intensity.

Conclusions: Unless there are well-thought out strategies for minimizing the undesirable impact on the environment, it is not advisable that such projects be permitted.

Keywords: Environmental Impact; Water; Transfer
\end{abstract}

\section{Background}

Water resource optimization is deemed essential for agricultural, industrial, and urban development, especially in developing countries. One of the main goals of the optimal planning of water resources is agriculture and drinking water supplies in which the collection and storage of precipitation and surface water in different fields are the most valuable executive program (1). To reach this goal, harnessing the water in border rivers and transferring it to central areas is also a part of the department of energy's strategy for water resource planning. In Iran, this strategy assumes an even greater significance given that vast swathes of the country are regarded as arid and semiarid. The preservation and storage of water resources and their optimal use are of vital importance and can have positive effects on economy, society, and culture (2). Also, the destruction of vegetation in the aquiferous basin, the harnessing of rivers through dam constructions, pollution caused with the discharge of sewage and utilization of sand and rivers, and river water transmission somehow affect the environmental changes (3). These adverse consequences can be regarded as a serious threat to human life because of their impact on economy and social life. Recent decades have witnessed a rise in environmental awareness and, thus, demands that appropri- ate measures be taken to monitor the environmental impacts of dams and to reduce the negative effects of dam construction (4). There are many instances of important projects having been accomplished in developing countries without sufficient environmental impact assessment reports. According to a study, what seems necessary now is the identification and monitoring of the impact of water resource development projects so that both benefits and risks are taken into account (5). The Aswan Dam in Egypt is one of the most prominent examples of water resource development schemes with a significant impact on the environment and eventually a motivating force behind an increase in environmental awareness. The environmental assessment had no important role at the stage of location survey during the construction of the dam (around 1960). It took many years to adopt and implement the relevant legislation in other countries (6). The laws pertaining to the environmental assessment were ratified in some countries as follows: Sweden in 1969; America in 1970; Canada in 1973; Australia and Malaysia in 1974; France in 1976; and India in 1994 (7). In Iran, the guidelines on environmental studies came into effect on 05/13/1994 and do not retrospectively include dams predating them.

Experts play a pivotal role in the monitoring of the op- 
eration of dams. Indeed, experts need to strive to adopt appropriate ways to reduce the negative environmental impacts of dam construction while investigating the present situation. Growth in the number of dams in Iran has been a source of concern for environmental experts in recent years. According to statistics, the number of dams built in the recent 100 years (especially the recent 4 years) has been increased dramatically, such that 53 dams have already been built, 68 dams are being constructed, and 121 dams are also under investigation. The majority of the functioning dams were designed and exploited with no environmental assessment $(8,9)$.

\section{Objectives}

The present study sought to evaluate the environmental impacts of the water transfer project of the Jooban Dam in two phases of preparation and operation.

\section{Materials and Methods}

In this report, the international committee on large dams (ICOLD) method was applied to evaluate the dams. In this method, dam construction activities and components of the environment are chosen in accordance with the forms and instructions issued by the ICOLD. Of the advantages of the ICOLD method is that it states the features of each effect on environment so that the signs and numbers used in this matrix will explain the condition and features of the effect. The reason for employing the ICOLD matrix in this report was to display the qualitative features of the effect on the components of environment, which is done by the use of symbols. The ICOLD matrix includes some lines and volumes. The lines of the matrix consist of two parts: the first one refers to dam construction activities and the second one is concerned with reforming and control activities for mitigating the negative effects. The volumes point to environmental components, including physical, biological, and socio-economic factors as well as environmental pollutions.

What is important and essential in environmental impact assessment is the intensity of the environmental impact of the water transmission system, which is dependent on the project goals, system status, type of transmission system (channels and tunnels), and volume of excavation and embankment. Apropos the technical options for the transmission system, there are two transmission path options for the tunnel in this project that were within a short distance from the last transmission path. However, by considering geological issues and with the aim of the suitability of the transmission path concerning its geological impacts on environmental issues and tunnel immunity, the last path was chosen. Table 1 depicts the guide to the sign and matrix numbers of the effects and Table 2 demonstrates a comparison between the severity of the positive and negative impacts in different dam construction projects.

\begin{tabular}{|c|c|}
\hline Effects Features & Sign and Matrix Numbers \\
\hline \multicolumn{2}{|l|}{ Types of Effect } \\
\hline Positive & + \\
\hline Negative & - \\
\hline \multicolumn{2}{|l|}{ Severity of the Effect } \\
\hline Poor effect & 1 \\
\hline Weak effect & 2 \\
\hline Moderate effect & 3 \\
\hline $\begin{array}{l}\text { Strong effect (beneficial or } \\
\text { harmful) }\end{array}$ & 4 \\
\hline $\begin{array}{l}\text { Strongest effect (beneficial } \\
\text { or harmful) }\end{array}$ & 5 \\
\hline \multicolumn{2}{|l|}{ Time of Effect } \\
\hline Immediately & I \\
\hline Long term & $\mathrm{L}$ \\
\hline \multicolumn{2}{|l|}{ Continuity of Effect } \\
\hline Temperate & $\mathrm{T}$ \\
\hline Permanent & $\mathrm{P}$ \\
\hline \multicolumn{2}{|l|}{ Probability of Effect } \\
\hline Certain & $\mathrm{C}$ \\
\hline Probable & M \\
\hline
\end{tabular}

\subsection{Introduction of the Study Area}

The study area is located in the west of Iran. The Jooban catchment covers an area of over 860 square kilometers to the south of the Kelas catchment. This basin is limited to the Zarrineh Rood in the east. Four rivers flow in this basin and they merge near the axis of the Jooban Dam. The Jooban River thereafter joins Kelas River before the latter flows out of the country. The annual average discharge of the Jooban River at the axis of the dam is 364.7 million cubic meters.

The principal aims of the first stage of the studies consist of supplying water requirement for more than 7000 hectares of agricultural land within the Jooban basin (up to 39 million cubic meters), providing about 5 million cubic meters of water for Baneh city annually, generating hydroelectric power, and transferring 237 million cubic meters of surplus from the Jooban water basin to the nearest adjacent catchment annually. The transferred water will be exploited to cover the needs of agriculture (over 35 hectares), industry, and drinking usage.

To address the concerns over the high length of the water transmission system, the high cost of construction, the supply of electricity requirement to the pumping station, the operation of the water transmission system, and the considerable time delay with respect to the time of the operation of the Jooban Dam, it seems prudent to construct a hydroelectric power plant for the more efficient use of the required investment at the Jooban Dam site to produce the hydroelectric energy between the time of the utilization of the Jooban Dam and the transmission system. 
Pazoki M et al.

\begin{tabular}{|c|c|c|c|c|c|c|c|c|c|c|c|c|}
\hline \multirow[t]{2}{*}{ Environment } & \multicolumn{2}{|c|}{ Results of Effect } & \multicolumn{3}{|c|}{ Probability of Effect } & \multicolumn{2}{|c|}{ Continuity of Effect } & \multicolumn{5}{|c|}{ Severity of Effect } \\
\hline & Positive & Negative & Certain & Probable & Improbable & Permanent & Temporary & Poor & Weak & Moderate & Strong & $\begin{array}{c}\text { The } \\
\text { strongest }\end{array}$ \\
\hline $\begin{array}{l}\text { Physico- } \\
\text { chemical } \\
\text { environment }\end{array}$ & 0 & 60 & 54 & 33 & 0 & 24 & 45 & 9 & 38 & 25 & 8 & 3 \\
\hline $\begin{array}{l}\text { Biological } \\
\text { environment }\end{array}$ & 0 & 39 & 24 & 24 & 0 & 22 & 24 & 29 & 18 & 7 & 5 & 0 \\
\hline $\begin{array}{l}\text { Socio- } \\
\text { economic } \\
\text { environment }\end{array}$ & 15 & 20 & 17 & 22 & 0 & 10 & 20 & 10 & 14 & 9 & 5 & 0 \\
\hline Sum & 15 & 119 & 95 & 79 & 0 & 56 & 89 & 48 & 70 & 41 & 18 & 3 \\
\hline
\end{tabular}

\subsection{Survey Research Method (Field Survey)}

In this part, about 50 experts were dispatched in different working groups and in several stages of the project to the site. They visited the study area to investigate it regarding biology and environmental pollution as well as its inhabitants' social, economic, and cultural status with a view to gaining an accurate insight. Additionally, a questionnaire was designed for interviews with the local people to collect more accurate data on their socioeconomic status. In the present study, environmental parameters were considered in the physical-biological and socio-economic aspects during both construction and operation.

The following presents the types of features expressed with the use of defined descriptors:

A) The type of effect on the project

Signs (+) and (-) represent the desirable and undesirable effects, respectively.

B) Descriptors of the intensity of the effect

These descriptors are divided into five categories:

1) Strongest effect: this is used for the work which causes severe and significant changes to the status quo in the matrix. The indicator is displayed with the numeric digit 5 .

2) Strong effect: this is used to describe the effects including when the amount of changes to the status quo is less than the strongest effect, albeit with a considerable amount. this indicator is displayed with the numeric digit 4.

3) Moderate effect: it describes an effect which is not so much as to be considered either a strong effect or a less value. This indicator is displayed with the numeric digit 3.

4) Weak effect: the effect in this category exerts less intensity and has minor changes in the status quo. This indicator is displayed with the numeric digit 2.

5) Poor effect: this effect may cause low rates of minor and insignificant changes in the environmental status quo. This indicator is displayed with numeric digit 1.

C) Probability of effect

1. Certain effects: this indicator is applied for the effects that are due to the current realities of the region and the similar activities proven by the expert team. This effect is displayed with the symbolic letter C.
2. Probable effects: this indicator is used for the effects that are not certain to have happened but their chance of occurrence is probable. This symbolic letter is $M$ in this matrix.

3. Improbable effects: this indicator indicates the effects that are unlikely to occur. The symbolic letter is $U$ in this matrix.

D) Continuity of effect

The effects that occur at a specific time and are temporary are called temporary effects and are displayed with the symbolic letter T. The effects that are permanent will be periodic or continuous and are displayed with the letter P.

E) Time of effect

The occurrence of all the effects in a project is not simultaneous: some affects may emerge immediately after the start of the activity, whereas some others may happen in a longer time (long term). Two symbolic letters, i.e. I and $\mathrm{L}$, represent the immediate and long-term effects, correspondingly.

Using the matrix in this report demonstrates the features and the quality of the effects on the environment via the use of the symbols listed above.

\section{Results}

Exploring the type of the effects and the consequences of the construction of the transmission system project on the local environment with the use of the proposed matrix method was conducted in two stages. Firstly, the effects of the various stages of the project were assessed in the construction and operation phases on the environmental factors and the area affected by the project, regardless of the improvement and control methods designed to diminish the adverse effects. The following table summarizes the anticipated effects of the transmission of the Jooban Dam system project in both preparation and utilization systems (Table 3).

Secondly, the proposed improvement and control methods and their efficacy in diminishing the negative effects and improving the environment during the construction and utilization processes were considered. It is worth bearing in mind that what constitutes the most important issue for assessment is the continuity of the effect. In the 
construction stage, more effects are usually temporary and short term. In the utilization phase, because of the long duration of the stage above, the effects are more permanent. Consequently, the significance of these effects is more important than that of its temporary effects.

A summary of the evaluation of the impact results of the matrix based on the results of the water transmission system, which was performed in two stages (i.e. without improvement actions and with improvement actions), is presented in Table 4 .

\section{Discussion}

In light of the matrix utilized in the present study, the following conclusions can be reached:

- In the first two stages of without improvement actions and with improvement actions, the respective numbers of the records loaded into the matrix (the whole number of the detected implications) were 224 and 326 . An increase of $70 \%$ in the impacts is a sign of the importance of the improvement actions in the assessment of this project.

- The numbers of the positive records in the first and sec- ond stages were respectively 22 and 97 . In the first stage, there were 12 permanent and 10 temporary records. Also, the sum of the positive impacts in the second stage comprised 85 permanent records and 12 temporary ones. Comparing the number of the positive records in the first and second stages showed that the number of the positive records with the improvement action resulted in a 4.41-time increase. In addition, the ratio of the permanent positive records to the total positive records was raised in both stages from 0.55 to 0.85 .

- There were 144 first negative and 145 second negative records. The above permanent and temporary records in the first stage were respectively 55 and 89 . The sum of the negative records in the second stage comprised 56 permanent and 89 temporary records. Comparing the number of the negative records in the first and second stages showed that the number of the negative records was raised by only $0.01 \%$ by the improvement actions.

- In the first and second stages, the ratio of the negative records to the total records was reduced from $30 \%$ to $21 \%$. Therefore, the negative records had a drop of about $9 \%$ due to the improvement actions.

\begin{tabular}{|c|c|c|c|c|c|c|c|c|c|c|c|c|}
\hline \multirow{2}{*}{$\begin{array}{l}\text { Environm } \\
\text { ent }\end{array}$} & \multicolumn{2}{|c|}{ Results of Effect } & \multicolumn{3}{|c|}{ Probability of Effect } & \multicolumn{2}{|c|}{ Continuity of Effect } & \multicolumn{5}{|c|}{ Severity of Effect } \\
\hline & Positive & Negative & Certain & Probable & Improbable & Permanent & Temporary & Poor & Weak & Moderate & Strong & $\begin{array}{c}\text { The } \\
\text { strongest }\end{array}$ \\
\hline $\begin{array}{l}\text { Physico- } \\
\text { chemical } \\
\text { environ- } \\
\text { ment }\end{array}$ & 28 & 10 & 50 & 14 & 0 & 37 & 6 & 6 & 20 & 33 & 4 & 2 \\
\hline $\begin{array}{l}\text { Biological } \\
\text { environ- } \\
\text { ment }\end{array}$ & 21 & 9 & 22 & 13 & 0 & 29 & 1 & 12 & 15 & 2 & 6 & 0 \\
\hline $\begin{array}{l}\text { Socio- } \\
\text { economic } \\
\text { environ- } \\
\text { ment }\end{array}$ & 13 & 9 & 11 & 14 & 0 & 19 & 5 & 2 & 8 & 9 & 3 & 2 \\
\hline Sum & 62 & 28 & 83 & 41 & 0 & 85 & 12 & 20 & 43 & 44 & 13 & 4 \\
\hline
\end{tabular}

Table 4. Contribution of $P$ and T Values according to their Severity (Percentage)

\begin{tabular}{|c|c|c|c|c|c|c|c|c|c|c|c|c|}
\hline \multirow{2}{*}{$\begin{array}{l}\text { Type of } \\
\text { Consequences }\end{array}$} & \multicolumn{6}{|c|}{ Negative Effects } & \multicolumn{6}{|c|}{ Positive Effects } \\
\hline & -5 & -4 & -3 & -2 & -1 & Sum & 1 & 2 & 3 & 4 & 5 & Sum \\
\hline \multicolumn{13}{|c|}{$\begin{array}{l}\text { With Improvement } \\
\text { Actions }\end{array}$} \\
\hline Permanent & 5.36 & 25.00 & 32.14 & 23.21 & 14.29 & 100 & 14.12 & 30.59 & 42.35 & 9.41 & 3.53 & 100 \\
\hline Temporary & 2.25 & 3.37 & 17.98 & 51.69 & 24.72 & 100 & 8.33 & 41.67 & 25.00 & 25.00 & 0 & 100 \\
\hline \multicolumn{13}{|c|}{$\begin{array}{l}\text { Without } \\
\text { Improvement Actions }\end{array}$} \\
\hline Permanent & 5.45 & 25.45 & 32.73 & 23.64 & 12.73 & 100 & 8.33 & 8.33 & 66.67 & 8.33 & 8.33 & 100 \\
\hline Temporary & 2.25 & 3.37 & 17.98 & 51.69 & 24.72 & 100 & 10.00 & 40.00 & 20.00 & 30.00 & 0 & 100 \\
\hline
\end{tabular}


Pazoki M et al.

Table 5. Literature Data on Environmental Impact Assessment in Dam Construction

\begin{tabular}{|c|c|c|}
\hline Authors & The Study Area & Results \\
\hline Han et al. (10) & South Korea & $\begin{array}{l}\text { The choice experiment approach was used to measure economic values for the individual } \\
\text { attributes of environmental impacts caused by large dam construction. The results illustrate } \\
\text { that there is a substantial non-market willingness-to-pay to mitigate multiple environmental } \\
\text { impacts by large dam construction. }\end{array}$ \\
\hline Fearnside (11) & Brazil & $\begin{array}{l}\text { The Santo Antonio and Jirau Dams on Brazil's Madeira River have severe impacts, but the } \\
\text { decision to build the dams was made before impacts were evaluated. Environmental impact } \\
\text { study (EIA) and other reports show a systematic tendency to minimize the importance of } \\
\text { these concerns. When benefits are presented, the tendency is to exaggerate. }\end{array}$ \\
\hline $\begin{array}{l}\text { Mudzengi et } \\
\text { al.(12) }\end{array}$ & Zimbabwe & $\begin{array}{l}\text { The study has revealed that the Siya Dam has both positive and negative socio-economic } \\
\text { impacts in the Mazungunye area. However, there is a need to enhance the beneficial impacts } \\
\text { and minimize the adverse impacts of the dam. The beneficial economic impacts of the dam } \\
\text { can be enhanced by developing local irrigation schemes. Lack of capital is the major hin- } \\
\text { drance to the development of the schemes. Funds should be made available for this purpose. }\end{array}$ \\
\hline This study & Iran & $\begin{array}{l}\text { In terms of the intensity of the effects, the negative effects are also superior to the positive ef- } \\
\text { fects. The most important reasons for this issue are the impacts of destruction of forests and } \\
\text { pastures and land deformation. Accordingly, the methods of reducing these effects are very } \\
\text { important. Therefore, the implementation of the project is rejected insofar as it fails to use } \\
\text { strategies for reducing the impacts and executing the improvement action. }\end{array}$ \\
\hline
\end{tabular}

- The sums of the permanent records in both first and second stages were -150 and 80 , respectively. The number of $(\mathrm{P})$ values in the first stages was 83 with an average ranking of - 0.47 ; nevertheless, in the second stage, the number of $(\mathrm{P})$ values and average ranking were 181 and + 0.32 , correspondingly.

- The sum of the positive records rose dramatically as a result of the improvement actions, denoting the importance of performing the improvement actions in this project.

- The sum of the temporary records in the first and second stages was -205 and -196, respectively. Therefore, the sum of the negative temporary records would be reduced by performing the improvement actions.

- In the first (i.e. without improvement actions) and second (with the improvement actions) stages, the negative permanent effects with an intensity of 5 comprised 5 numbers ( 3 permanent and 2 temporary) and the positive effects with an intensity of 5 consisted of one number. Deforestation and destruction of pastures, land deformation, and land utilization alteration were the causes of this issue, which cannot be fully compensated by performing the improvement actions.

- In the first stage (i.e. without improvement actions), in terms of the number of values, the negative values were superior to the positive values and also in terms of the intensity of the effects, the negative effects were superior to the positive effects. The most important reasons for this issue are the impacts of the destruction of forests and pastures and land deformation; accordingly, the methods of reducing these effects are very important.

- The above indicators show that the negative environmental and social impacts of the project were superior to the positive impacts in terms of type, numbers, and intensity. And the implementation of the project is rejected inasmuch as it fails to bring to bear strategies for reducing the impacts and executing the improvement action.
A comparison of the environmental impacts of dam construction between Iran and other countries is illustrated in Table 5. Both negative and positive impacts, which can be brought about by dam construction, are explained in the following Table 5 .

\section{Acknowledgements}

The authors would like to thank Dr. Omid Bozorg Haddad for his valuable assistance.

\section{Authors' Contributions}

Peyman Dalaei and Masoome Ahmadi Pari performed the sampling and analysis. Maryam Pazoki supervised the process and analyzed the data.

\section{Funding/Support}

This study was financially supported by the Department of Environment, University of Tehran, Tehran, IR Iran. The funders had no role in the study design, data collection and analysis, decision to publish, or preparation of the manuscript.

\section{References}

1. Birol E, Karousakis K, Koundouri P. Using economic valuation techniques to inform water resources management: a survey and critical appraisal of available techniques and an application. Sci Total Environ. 2006;365(1-3):105-22.

2. Brierley GJ, Fryirs K. River Styles, a Geomorphic Approach to Catchment Characterization: Implications for River Rehabilitation in Bega Catchment, New South Wales, Australia. Environ Manage. 2000;25(6):661-79.

3. Kingsford RT. Ecological impacts of dams, water diversions and river management on floodplain wetlands in Australia. Austral Ecol. 2000;25(2):109-27.

4. Dudgeon D. Large-Scale Hydrological Changes in Tropical Asia: Prospects for Riverine Biodiversity The construction of large dams will have an impact on the biodiversity of tropical Asian rivers and their associated wetlands. BioScience. 2000;50(9):793-806. 
5. Appiah-Opoku S. Environmental impact assessment in developing countries: the case of Ghana. Environ Impact Assess Rev. 2001;21(1):59-71.

6. Acharibasam JB, Noble BF. Assessing the impact of strategic environmental assessment. Impact Assess Project Appraisal. 2014;32(3):177-87.

7. Modak P, Biswas AK. Conducting environmental impact assessment in developing countries. United Nations University Press; 1999.

8. Tajziehchi S, Monavari SM, Karbassi A, Shariat SM. Development of New Model for Computation of External Costs of Hydropower Dams. OIDA Int J Sustain Dev . 2014;7(4):109-20.

9. Tahmasebi S, Afkhami SM, Takdastan A. Study of Chemical, Physi- cal and Microbial Quality of Gargar River, sw, Iran, Using NSF Water Quality Index.J Health Sci. 2011;3(4):55-64.

10. Han SY, Kwak SJ, Yoo SH. Valuing environmental impacts of large dam construction in Korea: An application of choice experiments. Environ Impact Assess Rev. 2008;28(4-5):256-66.

11. Fearnside PM. Impacts of Brazil's Madeira River Dams: Unlearned lessons for hydroelectric development in Amazonia. Environ Sci Policy. 2014;38:164-72.

12. Mudzengi BK, Ejide B, Tamuno SO, Iroh WO, Muchenje F, Moruff $\mathrm{M}$. An assessment of the Socio-Economic impact of the construction of Siya dam in the Mazungunye area: Bikita district of Zimbabwe.J Sustain Dev Afr. 2012;14(4):1-17. 